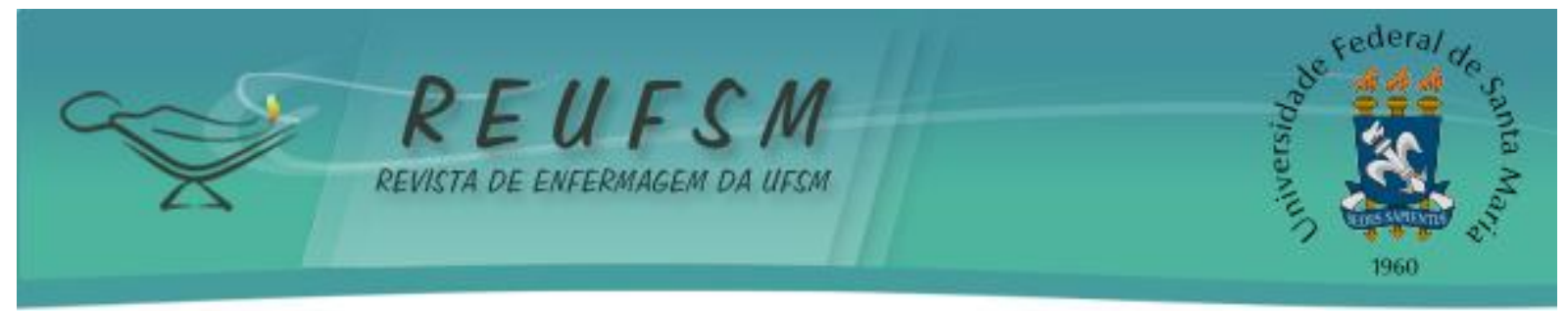

ARTIGO ORIGINAL

\title{
PERCEPÇÕES DE PROFESSORES ENFERMEIROS SOBRE A INTERSECÇÃO DO TRABALHO
} ASSISTENCIAL E DOCENTE

\section{PERCEPTIONS OF NURSE PROFESSORS ABOUT THE INTERSECTION OF ASSISTANTIAL AND TEACHING WORK}

\section{PERCEPCIONES DE PROFESORES ENFERMEROS SOBRE LA INTERSECCIÓN DEL TRABAJO ASISTENCIAL Y DOCENTE}

Doi: $10.5902 / 2179769210081$

Luiz Anildo Anacleto Silva ${ }^{1}$ Éder Luís Arboit ${ }^{2}$ Luís Antônio Müller ${ }^{3}$ Monique Prestes ${ }^{4}$ Indiara Sartori Dalmolin ${ }^{5}$ Marcelo Machado Sassi ${ }^{6}$

RESUMO: Objetivo: conhecer as percepções de professores enfermeiros sobre a importância da experiência assistencial em relação ao exercício do trabalho docente. Método: a pesquisa caracteriza-se como um estudo exploratório-descritivo, com abordagem qualitativa. Na apreciação dos dados, utilizou-se a análise de conteúdo. Os participantes da pesquisa foram sete professores universitários que, anteriormente à prática docente haviam tido experiência na assistência. Resultados: o estudo mostra que as experiências no campo da prática assistencial contribuem para o desenvolvimento de conteúdos, sobretudo no que se refere à intersecção entre teoria e prática. Conclusão: a experiência na assistência contribui, no que se refere ao ensino, em relacionar teoria e prática, contudo, isso não se evidencia em outras atividades como pesquisa e extensão.

Descritores: Enfermagem; Educação em enfermagem; Docentes de enfermagem; Prática do docente de enfermagem; Pesquisa em enfermagem.

ABSTRACT: Aim: to understand the perceptions of nurse professors about the importance of healthcare experience regarding to the exercise of teaching. Method: The study is characterized as a descriptive exploratory study with a qualitative approach. In evaluating the data we used content analysis. Survey participants were seven university professors prior teaching practice had experience in assisting. Results: The study shows that the experience in the field of health care practice, contribute to the development of content, especially as regards to the intersection between theory and practice, Conclusion: The

\footnotetext{
${ }^{1}$ Enfermeiro. Doutor em enfermagem. Professor adjunto no Departamento de Ciências da Saúde. Curso de Enfermagem. Universidade Federal de Santa Maria. Campus de Palmeira das Missões. E-mail: luiz.anildo@yahoo.com.br

${ }^{2}$ Enfermeiro, Mestrando do Programa de Pós-Graduação em Enfermagem da Universidade Federal de Santa Maria - PPGenf- UFSM, Especialista em Educação Profissional na área da Saúde: enfermagem, Saúde Coletiva e da Família; Terapia Intensiva e Gestão Hospitalar. Palmeira das Missões, RS, Brasil. E-mail: eder.arb@bol.com.br

${ }^{3}$ Enfermeiro, Mestrando do Programa de Pós-Graduação em Enfermagem da Universidade Federal de Santa Maria - PPGenf- UFSM, Especialista em Urgência, Emergência e Trauma, Cardiologia e Terapia Intensiva. Email: Ijuí, RS, Brasil. E-mail: mullerla@ibest@bol.com.br

${ }^{4}$ Enfermeira. Mestranda em Enfermagem do Programa de Pós-Graduação em Enfermagem da Universidade Federal de Pelotas. E-mail: moniprestes@hotmail.com

5 Enfermeira egressa da Universidade Federal de Santa Maria - Campus de Palmeira das Missões. E-mail: indiarasartoridalmolin@yahoo.com.br

${ }^{6}$ Enfermeiro egresso da Universidade Federal de Santa Maria - Campus de Palmeira das Missões. E-mail: sassimarcelomachado@hotmail.com
} 


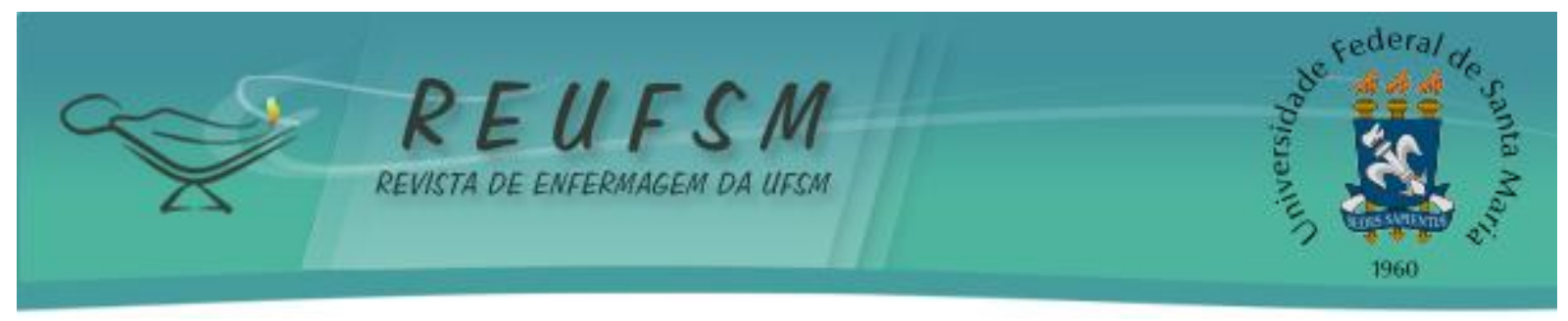

experience in assisting contributes with regard to education, to relate theory and practice, however, this is not evident in other activities such research an extension.

Descriptors: Nursing; Education nursing; Faculty, nursing; Nursing faculty practice; Nursing research.

RESUMEN: Objetivo: conocer las percepciones de los profesores enfermeros sobre la importancia de la experiencia asistencial en relación al ejercicio de la docencia. Método: La investigación se caracteriza como estudio exploratorio descriptivo con enfoque cualitativo. En la evaluación de los datos, se utilizó el análisis de contenido. Los participantes de la investigación fueron siete profesores universitarios que antes de la práctica docente habían tenido experiencia en la asistencia. Resultados: El estudio muestra que las experiencias en el campo de la práctica asistencial contribuyen al desarrollo de los contenidos, especialmente en lo que se refiere a la intersección entre teoría y práctica. Conclusión: La experiencia en la asistencia contribuye, con respecto a la enseñanza, a relacionar teoría y práctica, sin embargo, esto no se demuestra en otras actividades como investigación o extensión.

Descriptores: Enfermería; Educación en enfermería; Docentes de enfermería; Práctica del docente de enfermería; Investigación en enfermería.

\section{INTRODUÇÃO}

O sistema de ensino superior influencia a sociedade, ao mesmo tempo em que é influenciado por determinações histórico-sociais. O ensino superior, estrategicamente, está comprometido com o desenvolvimento do país, em razão do incremento de inovações tecnológicas, produção e propagação da ciência e da cultura, mas, sobretudo, na formação de pessoas, qualificação do trabalho e nos processos de modernização e melhoramento social. ${ }^{1}$ Embora a educação superior tenha sido criada com a vinda da família real portuguesa para o Brasil, no século XIX, o ensino da enfermagem ocorreu quase cem depois, com a implantação da Escola Profissional de Enfermeiros. Diferentemente de outras escolas, dentre essas os cursos de engenharia, medicina e direito, que buscavam a formação elitizada, a escola de enfermagem tinha como objetivo a formação de pessoal, a baixos custos, com o objetivo de dar assistência aos doentes mentais. ${ }^{2}$

Atualmente, as instituições de ensino superior, com destaque para os cursos da área da saúde, têm procurado inserir, nas suas propostas curriculares, a flexibilidade, a interdisciplinaridade, a contextualização, a vinculação de teoria e prática, assim como a valorização dos preceitos éticos, estéticos e políticos. A intenção está em transcender a formação técnica, privilegiando as abordagens ativas, crítica e reflexivas, de forma a construir competências políticas, éticas e técnicas. ${ }^{2}$

A ação docente é multifacetada, pois nela há o atrelamento de diferentes saberes, dentre os quais a prática social, as habilidades e as expectativas, que se entrecortam com a historicidade de vida dos professores. Os docentes continuamente estão produzindo saberes específicos, intercalados com diversos outros conhecimentos. ${ }^{3}$

Muitas mudanças no ensino da enfermagem estão vinculadas à efetiva participação do professor enfermeiro. Para tanto, se fazem necessárias contínuas capacitações de preparo técnico, teórico e pedagógico, inseridas no contexto econômico, político, social e cultural, para que efetivamente se promovam transformações no ensino da enfermagem. Uma das competências específicas para a docência no ensino superior está no domínio na área pedagógica. Desta forma, espera-se que o docente se aposse de quatro eixos: o conceito de ensino-aprendizagem; a concepção e a gestão do currículo; a compreensão da relação entre professor aluno e o embasamento da relação entre teorias e práticas. ${ }^{4}$ 


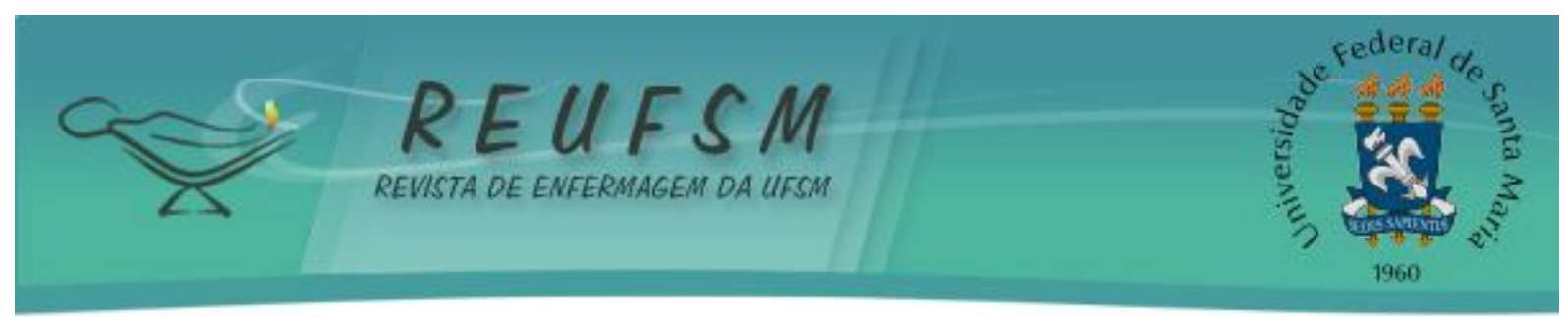

Do professor espera-se que tenha domínio dos conhecimentos básicos na área, experiência profissional, domínio do conceito de processo-aprendizagem, integração do desenvolvimento cognitivo, afetivo-emocional e de habilidades; assim como procurar desenvolver junto aos alunos os preceitos políticos e éticos que norteiam a profissão. Contudo, um dos atravessamentos que se observam nas universidades brasileiras, é a predileção pela formação técnico-científica em detrimento à formação didático-pedagógica. ${ }^{4}$

0 exercício da docência é amplo. A diversidade de conhecimentos necessita estar entremeada de teoria e prática. A formação de professores é um processo contínuo, que se estende por toda a carreira profissional, cujo desenvolvimento envolve contínuas aprendizagens, interativas e acumulativas que ocorrem dentro de uma variedade de aprendizagem. A formação de professores visa à formação docente comprometida com o ensino e a aprendizagem, mas, sobretudo, ancoradas na responsabilidade social. 0 trabalho docente é uma prática social, alicerçada que se faz no cotidiano dos sujeitos envolvidos, que nela se constituem como seres humanos. ${ }^{5}$

Um fato premente é a diferença do processo de trabalho assistencial e docente. 0 trabalho assistencial está calcado na gestão dos serviços e na assistência aos usuários, enquanto o processo de trabalho docente está vinculado ao ensino, à pesquisa e à extensão. Assim, o processo de trabalho acaba direcionando o desenvolvimento profissional.

De forma geral, para enfermeiros assistenciais o foco está no conhecimento técnico, na rotina e na repetição do trabalho, muitas vezes desenvolvidos de forma não crítica e não reflexiva, enquanto que no processo de trabalho docente, para viabilizar o ensino de forma efetiva, necessita-se a constante incorporação de novos conhecimentos, e a pesquisa e a extensão precisam ser fundamentadas teoricamente, assim como a produção científica. As discussões, a crítica e a reflexão, bem como as diferentes formas de pensar e agir, são bem-vindos à academia. No fazer docente, o aprender antecede o ensinar.

0 desenvolvimento deste estudo se justificou na necessidade de conhecer as intersecções entre trabalho assistencial e docente, na visão de professores oriundos dos serviços de saúde, pois se sabe que é concreta a diferença entre o processo de trabalho assistencial e a prática docente. Denota-se a migração de enfermeiros atuantes nos serviços hospitalares, na atenção básica e outras áreas para a academia, porém, raramente se observa o caminho inverso.

No ensino superior, requer-se a ação e a participação mais ativa de todos os sujeitos envolvidos no processo educativo, em razão de que a docência está comprometida com a formação de profissionais qualificados e socialmente engajados com a saúde e bemestar de pessoas, comunidades e populações. A pesquisa buscou responder à questão: Como os professores enfermeiros oriundos dos serviços percebem a importância da experiência assistencial para o ensino na enfermagem? Portanto, o objetivo da pesquisa foi conhecer as percepções de professores enfermeiros sobre a importância da experiência assistencial em relação ao exercício do trabalho docente.

\section{MÉTODO}

A pesquisa é de natureza exploratória e descritiva ${ }^{6}$, com abordagem qualitativa. ${ }^{7}$ A seleção dos sujeitos ocorreu de modo intencional ou deliberado. ${ }^{8}$ Como critérios de seleção e inclusão, foram eleitas as condições de ser docente efetivo do curso de enfermagem e participar voluntariamente do estudo; assinar o Termo de Consentimento Livre e Esclarecido e ter tido experiência mínima de um ano na assistência/administração em enfermagem, anteriormente ao exercício docente. 0 número de entrevistados foi considerado saturado quando o objetivo da pesquisa foi alcançado.

Os dados foram coletados no período de outubro a dezembro de 2012. O instrumento constou de entrevistas semiestruturadas, as quais foram gravadas 


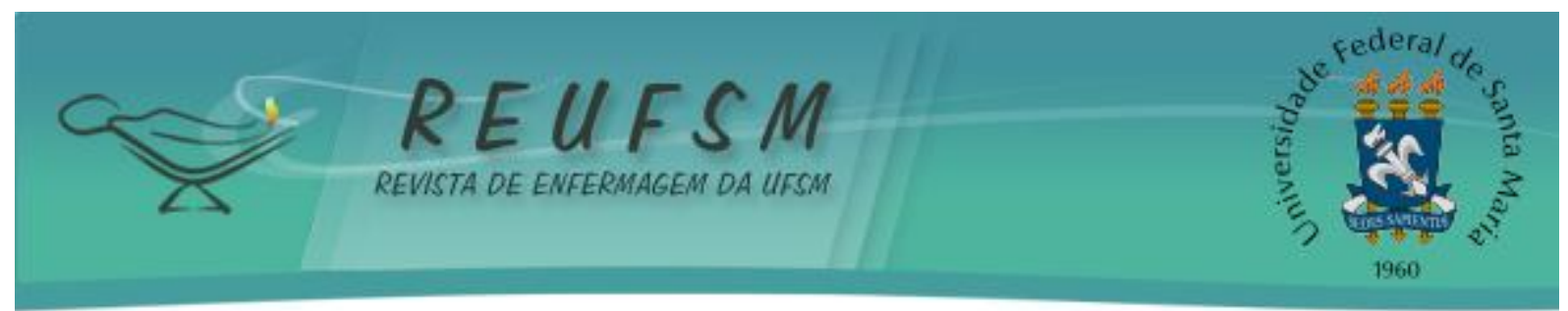

digitalmente, transcritas e validadas pelos sujeitos do estudo. Na apreciação dos dados, utilizaram-se os preceitos da análise de conteúdo. ${ }^{9}$ A pesquisa obedeceu aos aspectos éticos que envolvem pesquisas com seres humanos, em conformidade com o que prevê a Resolução do Conselho Nacional de Saúde, Portaria 196/96. ${ }^{10}$ A realização da pesquisa foi aprovada pelo Comitê de Ética em Pesquisa da Universidade Federal de Santa Maria (Parecer consubstanciado $n^{\circ}$ 23081.001363/2009-51).

\section{RESULTADOS}

Dos 21 docentes enfermeiros pertencentes a um curso de enfermagem de uma universidade pública, sete configuram-se dentro dos critérios de elegibilidade, anteriormente definidos. Os docentes restantes não se adequaram aos critérios estabelecidos e foram excluídos. Dos selecionados constam um sujeito do sexo masculino e seis femininos, sendo dois doutores e cinco mestres (seis desses em processo de doutoramento). A média de idade dos entrevistados é de 45 anos, com experiência média de 11 anos na assistência e 16 na docência. Quatro docentes tiveram concomitantemente experiência assistencial e docente, enquanto três tiveram experiência sequencial, entre a assistência e a docência. Os sujeitos do estudo estão identificados com o código (D) de docente e sequencialmente numerados.

Os dados advindos da pesquisa permitiram a construção de várias categorias, contudo, em razão da limitação de espaços, optou-se por um recorte, no qual se evidenciou a categoria inter-relação teoria e prática.

\section{A inter-relação teoria e prática no trabalho docente}

A percepção docente sobre a realidade vivida permite dosar o desenvolvimento dos preceitos teóricos e práticos, ao incluir o aluno no processo de ensino-aprendizagem, como forma de superação da dicotomia teoria/prática, valorizando o trabalho articulado com os serviços, com as necessidades de saúde das populações e com o desenvolvimento do trabalho interdisciplinar. Um dos entrevistados afirma que

O enfermeiro docente tem que ter um cuidado para não ter esse distanciamento da teoria e da prática, trazer muita teoria para o aluno pode se distanciar da realidade. (D1)

Compreender a relação entre teoria e prática, as inter-relações com os serviços, a interdisciplinaridade e as necessidades dos usuários permite a reflexão entre o que se aprende em sala de aula e o que se executa nas práticas e estágios e, desta forma, pode-se aprimorar o aprendizado.

A superação de modelos educativos busca, na interdisciplinaridade formas de contribuir para um agir educativo mais produtivo, com construções coletivas e crítica de novos saberes. Para tanto, supõe-se a integralização em detrimento a superposição de disciplinas. ${ }^{11}$

Fui enfermeira assistencial e, concomitantemente, docente e essa inter-relação me ajudou muito mais na assistência do que na docência, tanto quanto, porque na assistência se é mais operacional, enquanto que a docência exige que se estude mais. Eu fui muito feliz na realidade, porque assim, na realidade, eu ia dar aula e ainda hoje eu dou baseada na minha experiência vivenciada. (D2) 


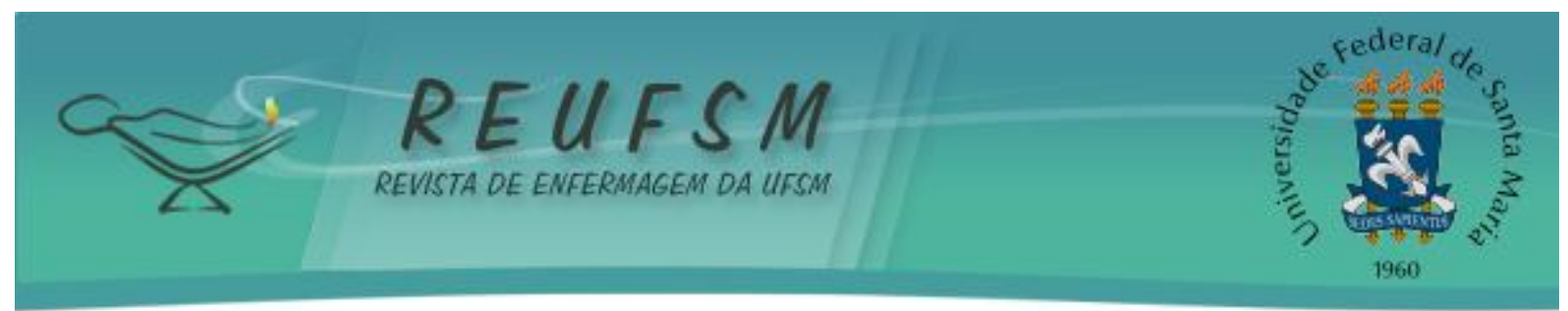

A integração entre a docência/assistência pode ser entendida como o desenvolvimento de um trabalho conjunto, situação em que o docente articula o trabalho de saúde do local com as atividades dos estudantes de enfermagem, instigando o diálogo e as mudanças em conformidade com as realidades vivenciadas. ${ }^{12}$

Para um dos entrevistados, a associação entre as ações assistenciais e docentes permite maior aproximação entre teoria e prática, situação essa que subsidia a ação assistencial:

Então é mais desafiadora mesmo, e com certeza a questão da parte prática, eu acredito que o enfermeiro docente, se ele teve a parte pratica, ele tem essa parte teórica mais associada, ele consegue fazer a associação entre a parte prática e a parte teórica e ter mais clareza na hora de passar para os alunos. (D6)

$\mathrm{Na}$ organização do processo de trabalho e, mais especificamente, na ação educativa, o docente precisa saber articular e dosar a oferta dos preceitos teóricos e práticos. Necessita ser o mediador do processo de ensino-aprendizagem, pois é a teoria que sinaliza os caminhos das práticas. Contudo, precisa-se ter cautela, pois o excessivo tecnicismo na formação em saúde e, de forma especial, na enfermagem, tende a colocar em planos periféricos a formação crítica, reflexiva e contextualizada das necessidades dos trabalhadores, sujeitos e populações. A valorização das práticas é evidenciada quando se afirma que

[...] vemos muita diferença do docente que tem uma experiência de prática com aquele que não tem e acaba centrando muito na teoria, então acho que tem que ter esse casamento, a gente precisa ir para $o$ campo da prática. A experiência da assistência é que me deu a sustentação para a docência, eu não tenho a menor duvida disso. (D3)

No processo educativo, é preciso transcender a discussão sobre teoria e prática. 0 docente ocupa um importante papel, enquanto mediador, facilitador e, principalmente, no que se refere à sistematização de atividades teórico-práticas. Nesta perspectiva, cabe ao docente instigar, articular e dinamizar o processo educativo, pela possibilidade de uso de estratégias interativas e dialógicas, como a problematização e a socialização de vivências entre as equipes de saúde, ancoradas nas necessidades das famílias e populações. ${ }^{13}$

A docência exige, para além da incorporação de conhecimentos, também a reflexão entre as concepções teóricas e práticas, que é favorecida pela academia, facilitando esse tipo de construção, pois a constante atualização docente é um dos fundamentos para a qualificação discente.

A docência traz para a gente a reflexão, a leitura, a atualização, com a docência, e a interação com os alunos, mas eu sinto muito a responsabilidade, pois são indivíduos que irão se formar profissionais, e logo ali eles vão atuar no campo de prática. (D4)

O fato de estar na docência necessita da constante incorporação de conhecimentos, ou seja, de continuamente se adquirir conhecimentos para sustentar as práticas. As experiências assistenciais, nesse caso, permitem, ao docente, fazer as aproximações na relação teoria/prática e, sobretudo, refletir sobre as formas de abordagem educativa. 


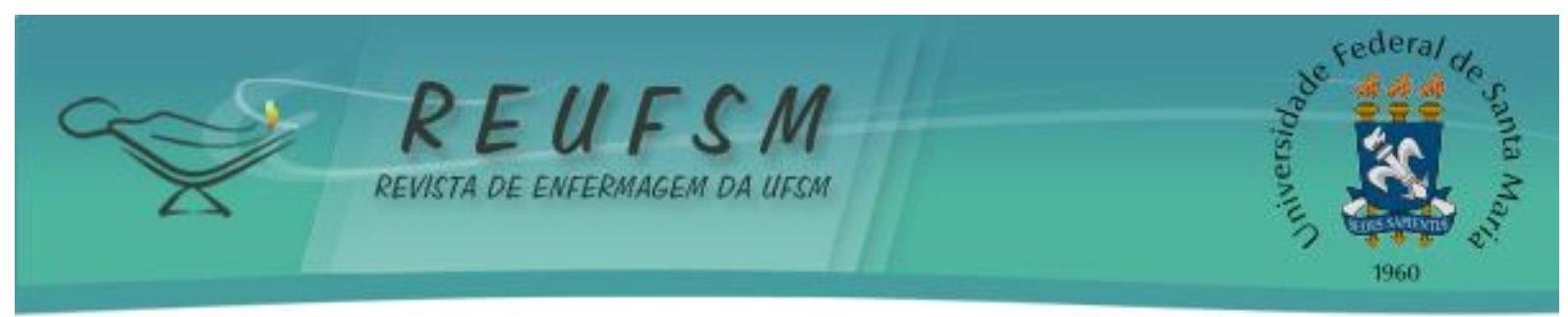

É mais desafiadora mesmo e, com certeza, a questão da parte prática vem me dando um olhar diferente pra docência. Então eu acredito que o enfermeiro docente, (pausa), se ele teve a parte prática, ele tem essa parte teórica mais associada, ele consegue fazer a associação entre a parte prática e a parte teórica e ter mais clareza na hora de passar para os alunos. (D5)

Então toda a vida da enfermagem eu acho que a gente tem que estudar e na docência muito mais, porque a gente está formando outras pessoas. Então, tem que estar sempre se atualizando, as coisas mudam muito, as técnicas mudam, o conhecimento $e$ as tecnologias novas, aparelhos novos, tratamentos, então tem que ir se atualizando; se parar de estudar, então, está fora. (D7)

A ação assistencial no campo da prática necessita estar vinculada a uma linha integradora para onde convergem os conteúdos teóricos que se concretizam através de situações reais, na qual há reciprocamente a retroalimentação das atividades teóricas e práticas. ${ }^{14}$ A repetição das técnicas traz habilidades, rapidez e, acima de tudo, segurança, mas somente a reflexão sobre o saber e o fazer permitirá interlocuções entre teoriaprática-teoria capazes de constituir uma práxis. A práxis pode ser entendida como um conjunto de relações de produção e trabalho que constituem uma estrutura social, estando a reflexão vinculada às transformações sociais. ${ }^{15}$

A articulação entre ensino e serviço, principalmente com a agregação da pesquisa, permite potencializar a formação e, também, a educação permanente dos trabalhadores. A articulação da pesquisa com o ensino e os serviços de saúde pode se constituir em importante estratégia pedagógica para a o desenvolvimento da capacidade de construir conhecimento e, concomitantemente, qualificar a assistência em saúde. Embora se reconheça que a pesquisa está vinculada à academia e a assistência aos serviços de saúde, essa dicotomia faz com que haja um modelo de formação dissociado da prática, gerando um fosso entre a formação e as diversas modalidades de práticas que se materializam nos serviços. ${ }^{16}$

A docência requer o envolvimento efetivo e afetivo do estudante, como autor e protagonista de sua própria história. Por isso, uma metodologia participativa estimula a criatividade e a iniciativa, que se tornam estratégias indispensáveis para a atuação docente em vista da aprendizagem e da formação profissional do estudante. ${ }^{11}$ Nessa circunstância, o docente pode influenciar de forma significativa no ensino-aprendizagem, de forma a aprimorar sua capacidade didático-pedagógica, fazendo com que o educando traga para a sala de aula suas experiências, em concordância com as diversidades encontradas no âmbito universitário. ${ }^{15}$

As novas demandas para o ensino e o aprendizado na enfermagem estão consignadas à interdisciplinaridade com outras áreas do conhecimento, o que implica a transcendência dos modelos setoriais de saberes em prol de práticas educativas de enfermagem comprometidas com as necessidades sociais. ${ }^{13} \mathrm{~A}$ ação educativa não se reduz à transmissão de conhecimentos, considerando-se que as práticas integram diferentes saberes, ou, melhor dizendo, os saberes docentes são temporais, plurais e heterogêneos. ${ }^{3}$

A formação em enfermagem está vinculada a alguns princípios: o compromisso e a responsabilidade social; a constituição de conhecimentos que habilitem os sujeitos a trabalhar na multidisciplinaridade em sua prática profissional; e, de igual modo, o desenvolvimento de ações profissionais que tenham como base o conhecimento clínico e saibam articular os preceitos teóricos com as práticas profissionais. ${ }^{4}$

A formação de professores é continuamente construída, pois se desenvolve e aperfeiçoa durante toda a sua trajetória profissional, na qual se articulam diferentes 


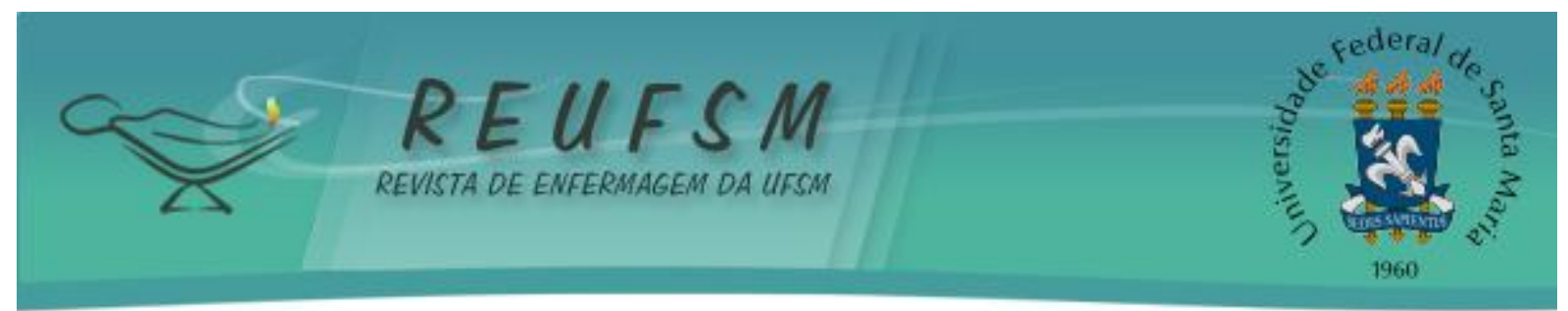

saberes, entre as quais a teoria e a prática, a troca de experiências, a formação continuada, o preparo teórico e instrumental. Nas atividades docentes, os saberes são adquiridos, processados, reprocessados e difundidos e é justamente nessa processualidade que os sujeitos se constituem docentes. ${ }^{3}$

A política de formação de recursos humanos de nível superior, na qual há uma continuidade vertical a partir da graduação, mestrado e doutorado, é destacada por um dos entrevistados como um fator que pode restringir a intersecção entre a teoria e a prática. Para ele, no preparo docente, a experiência na assistência é preponderante na formação em enfermagem.

O docente enfermeiro precisa ter passado pela assistência, independente de que área for. Eu não concordo muito, por mais que a CAPES (Coordenação de Aperfeiçoamento de Pessoal de Nível Superior) prevê hoje, como a questão das pessoas se formarem mestres e doutores muito precocemente, eu acho que precisa da assistência, é ela que dá sustentação para a docência, no meu ponto de vista. (D3)

No Brasil, os programas de pós-graduação buscam formar profissionais voltados à docência e, em especial, a pesquisa. A CAPES é um órgão do Ministério da Educação e Cultura (MEC) que tem como função primordial a expansão e consolidação da pósgraduação strictu sensu (mestrado e doutorado), tendo como objetivo maior o desenvolvimento científico e tecnológico e o preparo para a docência. ${ }^{3}$ A articulação entre o ensino, a pesquisa e a extensão representa uma importante forma de aprendizado, principalmente no que tange à transcendência à formação técnica, mais precisamente na constituição de constructos teóricos que proporcionem aos sujeitos em intervir profissionalmente nos mais diferentes espaços. ${ }^{17}$

A rápida atualização estrutural na formação do conhecimento e no aprimoramento de técnicas e procedimentos em saúde exige um olhar diferenciado, nos planos da investigação e da ação crítica e reflexiva no seu campo de atuação. Para que haja a intersecção entre teoria e prática, os programas de mestrado precisam ser constituídos de modo que facilitem essa aproximação e permitam aos sujeitos envolverem-se no contexto social em que estão inseridos e, assim, estabelecerem vínculos entre a prática profissional e a dinâmica social. ${ }^{18}$

Concomitantemente às suas funções, os programas de pós-graduação fazem emergir ações de fortalecimento recíproco, mediante a integração de ações docentes, discentes e assistenciais entre profissionais de enfermagem. As oportunidades de interação com professores de outras universidades, já com programas consolidados, a participação em bancas, rodas de conversas, seminários, jornadas e workshops, além de outras atividades que potencializam a produção do conhecimento, qualificando profissionais nas áreas de ensino, gestão, pesquisa e, principalmente, o desenvolvimento de novas tecnologias. ${ }^{19}$

Retomando, pode-se entender que as experiências dos docentes na área assistencial sejam válidas nas formas de abordar os conteúdos teóricos em relação às práticas. A intersecção de teoria/prática permite ao aluno incorporar conhecimentos mediados entre o que se propõe em sala de aula e o que se realiza nos espaços de trabalho. Contudo, precisa-se ressaltar que a política de formação proposta pela CAPES, embora privilegie a formação e o aperfeiçoamento docentes, principalmente no que tange à pesquisa e à extensão, não exclui as experiências profissionais, até por que essas são preponderantes na aproximação entre a teoria e prática.

A integração entre ensino, pesquisa e serviços se apresenta como uma importante estratégia de aperfeiçoamento dos modelos de formação, de educação no trabalho e, 


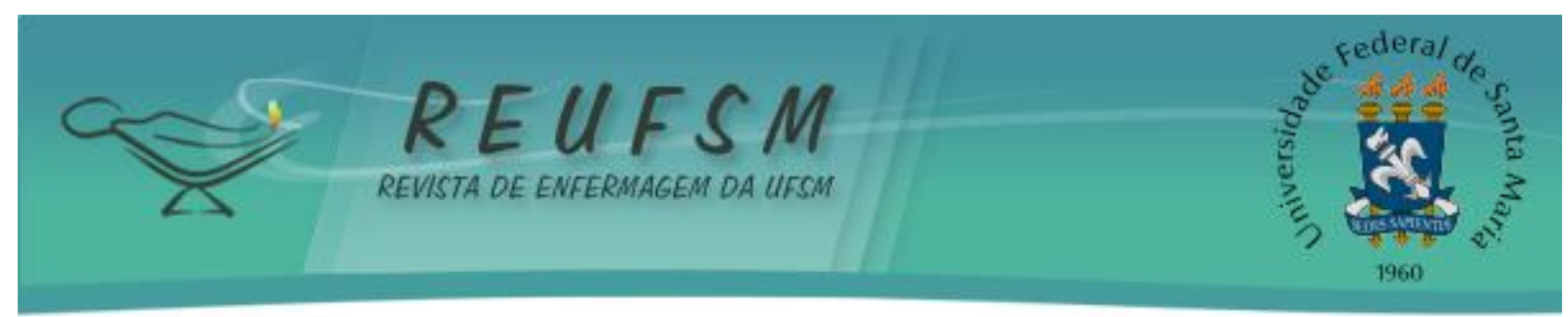

principalmente, da gestão do conhecimento na saúde. O desenvolvimento de novos processos que impulsionem a integração entre a academia e os serviços e práticas multidisciplinares, intersetoriais e interinstitucionais representa um importante avanço na construção de novos conhecimentos em saúde. ${ }^{16}$

Considera-se a integração entre alunos de pós-graduação e de graduação como uma importante estratégia de ensino-aprendizagem, em razão de que facilita a troca de experiência e permite ao pós-graduando inserir-se no contexto da formação profissional em sua área. No preparo do aluno da pós-graduação, mestrado e doutorado, a interação com alunos de graduação permite aos pós-graduandos a oportunidade de confrontarem sob uma nova perspectiva, as mudanças nos processos educativos. ${ }^{20}$

As experiências dos docentes na área assistencial repercutem nas novas formas de abordar os conteúdos teóricos em relação as respectivas práticas. Essa interação permite ao aluno incorporar conhecimentos mediados entre o que se propõe e o que se realiza nos espaços de trabalho.

\section{CONCLUSÃO}

Há aproximadamente duas décadas, muitos docentes enfermeiros advinham dos serviços de saúde, sejam esses hospitalares ou de saúde pública. Com as mudanças ocorridas, decorrentes de políticas de formação de pessoal, e a inserção da enfermagem nos mais diferentes cenários, eclodiram cursos de pós-graduação strictu sensu em diversas universidades, sejam públicas ou privadas, principalmente em razão da implantação dos mestrados interinstitucionais, o que implicou novos direcionamentos na formação em enfermagem; ou seja, se há algum tempo formavam-se enfermeiros para atuar assistência, atualmente, houve desdobramentos que naturalmente incluíram a formação universitária articulada com o momento vivido e vinculada às demandas sociais. Hoje, a formação dos docentes, na maioria dos casos, advém diretamente da academia, situação em que os estudantes se iniciam na extensão e, em especial, na pesquisa, e dão seguimento na sua formação, com a ascensão aos cursos de mestrado e doutorado.

O trabalho assistencial está pautado no cumprimento de determinadas ações/atividades relacionadas ao cuidado direto aos usuários, enquanto o trabalho docente se alicerça nas atividades de ensino, pesquisa e extensão, tendo como propósito primordial o preparo de profissionais críticos e reflexivos para prestar assistência aos usuários, conforme suas necessidades e demandas sociais que envolvem o processo de saúde e doença, em sintonia com as políticas de saúde, a condição econômica, o contexto social e, principalmente, de acordo com as necessidades de saúde dos sujeitos e ou populações.

Além disso, o processo de trabalho dos enfermeiros atuantes na assistência e na academia é diferenciado em relação a vários fatores, principalmente no que diz respeito à natureza do trabalho, à forma de organização, ao processo de trabalho, ao objeto, ao dimensionamento de pessoal, à produção e ao resultado do trabalho. Por essa razão, os docentes oriundos dos serviços, precisam refazer sua forma de pensar e agir e, sobretudo, no que se refere à inter-relação e a prática e, de maneira especial, constituir-se pesquisador.

As experiências, portanto, independente da área de atuação, quando conseguem agregar conhecimentos teóricos vivenciados com as práticas, podem constituir novas formas de saber e fazer. Isso porque a repetição do fazer diário, de forma acrítica e não reflexiva, sem a incorporação de novos conhecimentos, leva meramente à reprodução, e reproduzir sem experimentar é ação que não se configura em experiência, pois prática pela prática encerra-se em si mesma, enquanto que as práticas ancoradas nas teorias permitem o contínuo refazer. 


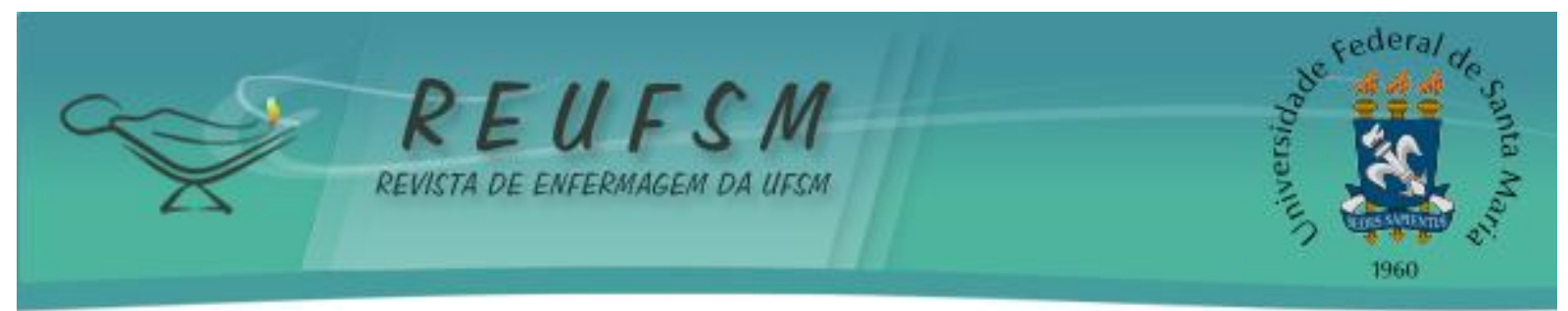

Por fim, é possível que afirmar que a experiência assistencial é muito importante na concepção dos entrevistados, que de uma forma geral valorizam os conhecimentos advindos da assistência, por contribuírem em especial apenas em uma parte específica do processo de trabalho docente. Também é possível ressaltar que, embora a prática assistencial, não seja uma pré-condição para a formação do docente em enfermagem, ela é considerada quase que imprescindível pelos entrevistados, pois apesar do trabalho docente não estar calcado, tão somente no ensino, é sobretudo na inter-relação social, através das atividades de extensão e, de modo especial, a pesquisa, que a relação teoriaprática-teoria se efetiva, potencializando a construção coletiva de novos saberes.

\section{REFERÊNCIAS}

1. Leonello VM, Miranda Neto MV, Oliveira MAC. A formação superior de Enfermagem no Brasil: uma visão histórica. Rev Esc Enferm USP [Internet]. 2011[acesso em 2013 jun 21];45(N Esp 2):1774-9. Disponível em: <http://www.scielo.br/scielo.php?script=sci_arttext\&pid=S0080 62342011000800024\&lng=en\&nrm=iso $>$.

2. Scherer ZAP, Scherer EA. Identificação dos pilares da educação na disciplina integralidade no cuidado à saúde. Rev Esc Enferm USP [Internet]. 2012 [acesso em 2013 jun 21];46(4):98593. Disponível em: <http://www.scielo.br/scielo.php?script=sci_arttext\&pid=S008062342012000400029\&lng=en\&nrm=iso>.

3. Backes VMS, Moya JLM, Prado ML. The construction process of pedagogical knowledge among nursing professors. Rev Latinoam Enferm [Internet]. 2011 [acesso em 2013 jun 21];19(2):421-8. Disponível em: <http://www.scielo.br/scielo.php?script=sci_arttext\&pid=S0104$11692011000200026 \&$ lng=en\&nrm=iso.

4. Rodrigues MTP, Mendes Sobrinho JAC. Enfermeiro professor: um diálogo com a formação pedagógica. Rev Bras Enferm [Internet]. 2007 ago [acesso em 2014 fev 13];60(4):456-9. Disponível em: http://www.scielo.br/scielo.php?script=sci_arttext\&pid=S0034$71672007000400019 \&$ lng $=$ en.

5. Madeira MZA, Lima MGSB. A prática pedagógica das professoras de enfermagem e os saberes. Rev Bras Enferm [Internet]. 2007 [acesso em 2014 fev 13];60(4):400-4. Disponível em: http://www.scielo.br/pdf/reben/v60n4/a08.pdf.

6. Gil AC. Como elaborar projetos de pesquisa. $4^{\mathrm{a}}$ ed. São Paulo: Atlas; 2008.

7. Minayo MCS. O desafio do conhecimento: pesquisa qualitativa em saúde. $12^{a}$ ed. São Paulo: Hucitec; 2010.

8. Fontanella BJB, Luchesi BM, Saidel MGB, Ricas J, Turato ER, Melo DG. Amostragem em pesquisas qualitativas: proposta de procedimentos para constatar saturação teórica. Cad Saúde Pública [Internet]. $2011 \mathrm{fev}$ [acesso em $2014 \mathrm{fev}$ 19];27(2):388-94. Disponível em: http: / / www.scielo.br/scielo.php?script=sci_arttext\&pid=S0102-

311X2011000200020\&lng=en.

\section{Bardin L. Análise de conteúdo. São Paulo: Edições 70; 2011.}

10. Brasil. Ministério da Saíude. Conselho Nacional de Saúde. Resolução CNS n 196, de 10 de outubro de1996. Diretrizes e normas regulamentadoras de pesquisas envolvendo seres humanos. Brasília(DF): Ministério da Saúde; 1996.

11. Almeida MM, Morais RP, Guimarães DF, Machado MFA, Diniz RCM, Nuto SAS. Da teoria à prática da interdisciplinaridade: a experiência do Pró-Saúde Unifor e seus nove cursos de 


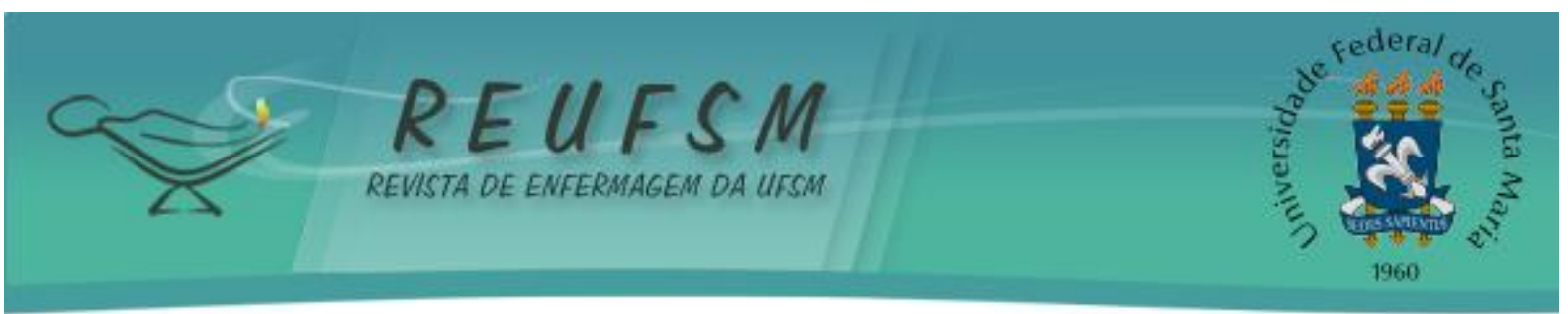

graduação. Rev Bras Educ Med [Internet]. 2012;36(1 Supl 1):119-26. Disponível em: http: //www.scielo.br/scielo.php?script=sci_arttext\&pid=S0100-

$55022012000200016 \& \operatorname{lng}=$ en\&tlng=pt.

12. Piexak DR, Backes DS, Santos SSC. Cuidado de enfermagem para enfermeiros docentes na perspectiva da complexidade. Rev Gaúcha Enferm [Internet]. 2013 jun [acesso em 2014 fev 13];34(2):46-53. Disponível em: Available from: http://www.scielo.br/scielo.php?script=sci_arttext\&pid=S1983$14472013000200006 \&$ ing $=$ en.

13. Backes DS, Grando MK, Gracioli MSA, Pereira AD, Colomé JS, Gehlen MH. Vivência teórico-prática inovadora no ensino de enfermagem. Esc Anna Nery [Internet]. 2012 set [acesso em $2014 \mathrm{fev}$ 14];16(3):597-602. Disponível em: http://www.scielo.br/scielo.php?script=sci_arttext\&pid=S1414$81452012000300024 \& \operatorname{lng}=$ en.

14. Rodrigues RAP, Erdmann AL, Silva IA, Fernandes JD, Araújo TL, Vianna LAC, et al. Doctoral education in nursing in Brazil. Rev Latinoam Enferm [Internet]. 2008 Aug [acesso em 2013 Jun 28];16(4):665-71. Disponível em: http://www.scielo.br/scielo.php?script=sci_arttext\&pid=S0104$11692008000400003 \&$ lng $=$ en.

15. Silva LAA, Ferraz F, Lino MM, Backes VMS, Schmidt SMS. Educação permanente em saúde e no trabalho de enfermagem: perspectiva de uma práxis transformadora. Rev Gaúcha Enferm. 2010;31(3):557-61. http://seer.ufrgs.br/RevistaGauchadeEnfermagem/article/view/12738/10889.

16. Ellery AEL, Bosi MLM, Loiola FA. Integração ensino, pesquisa e serviços em saúde: antecedentes, estratégias e iniciativas. Saude Soc [Internet]. $2013 \mathrm{mar}$ [acesso em $2014 \mathrm{fev}$ 15];22(1):187-96. Disponível em: http://www.scielo.br/scielo.php?script=sci_arttext\&pid=S0104$12902013000100017 \&$ Ing $=$ en.

17. Backes DS, Marinho M, Costenaro RS, Nunes S, Rupolo I. Repensando o ser enfermeiro docente na perspectiva do pensamento complexo. Rev Bras Enferm [Internet]. 2010 jun [acesso em 2013 ago 24];63(3):421-6. Disponível em: http://www.scielo.br/scielo.php?script=sci_arttext\&pid=S0034$71672010000300012 \&$ lng $=$ pt.

18. Ramos FRS, Backes VMS, Backes DS, Schneider DG, Pinheiro G, Zeferino MT, et al . Formação de mestres em enfermagem na Universidade Federal de Santa Catarina: contribuições sob a ótica de egressos. Rev Bras Enferm [Internet]. 2010 jun [acesso em 2013 jul 5];63(3):359-65. Disponível em: http://www.scielo.br/scielo.php?script=sci_arttext\&pid=S0034$71672010000300002 \&$ tng $=$ pt.

19. Linch GFC, Ribeiro AC, Guido LA. Programa de pós-graduação em enfermagem da Universidade Federal de Santa Maria: trajetória e resultados. Rev Gaúcha Enferm [Internet]. 2013 mar [acesso em 2013 ago 24];34(1):147-54. Disponível em: http://www.scielo.br/scielo.php?script=sci_arttext\&pid=S1983-

14472013000100019\&lng=pt.

20. Pimentel V, Mota DDCF, Kimura M. Reflexões sobre o preparo para a docência na pós-graduação em enfermagem. Rev Esc Enferm USP [Internet]. 2007 [acesso em 2013 ago 24]; 41(1):161-4. Disponível em: http://www.scielo.br/scielo.php?pid=S0080-62342007000100022\&script=sci_arttext.

Data de recebimento: $26 / 07 / 2013$

Data de aceite: 03/04/2014

Autor correspondente: Luiz Anildo Anacleto Silva. Universidade Federal de Santa Maria. Campus de Palmeira das Missões. Av. Independência, n 3751, Bairro Vista Alegre, Palmeira das Missões, RS - Brasil. CEP: 98300-000 - E-mail: luiz.anildo@yahoo.com.br 